seen at the level of the 10th and 12th thoracic segments. The skull is typical of anencephaly. The lateral radiographs dispose of the impression gained from the antero-posterior aspect, that the femora and tibiae are achondroplasic.

Acknowledgment.-Thanks are offered to Dr. Abbie for assistance with the histology; to Dr. Oxenham for interpreting the radiographs; and to Mr. Woodward Smith for the photographs.

\title{
THE SCHOOL OPHTHALMIC SERVICE
}

BY

Austin FuRniss, D.P.H., L.D.S.

SENIOR ASSISTANT SCHOOL MEDICAL OFFICER, WEST HAM

THE eye and the ear are the chief gateways of learning, therefore defects here are of prime importance. Impaired eyesight is one of the commonest and most potent defects which stand in the way of a child's school education. A service for the treatment of a particular condition or defect can only be made comprehensive by an efficient organisation in which the ascertainment of children suffering from that defect is complete. The earlier the ascertainment, the better the results of treatment. This applies to many other conditions besides defective vision, crippling defects being a good example. It is very important that arrangements should be fully developed for the ascertainment of defective vision and eye disease in children below school age. In the case of children under five years of age suffering from these defects the chief means of ascertainment is by the home visits of Health Visitors of the Maternity and Child Welfare Authority. The health visitors visit all homes (with the exception of the well-to-do) within fourteen days after the birth of the child, and thereafter periodically up to the age at which the child enters school. The health visitor inquires into the general condition of the child, and invites the mother to attend the infant welfare centre where an examination by a medical officer would be carried out. In the course of this work, the health visitors would become aware that a child was suffering from blindness, obvious squint, and inflammatory disease of the eye, and such a child would be referred for examination and treatment. Children known to be suffering from severe defective vision or eye disease should be notified to the Education Authority before admission to school. The Education Authority is then forewarned and can make suitable arrangements for any special medical or educational treatment at the earliest possible moment. In rural areas the health visitors can 
only visit the homes at infrequent intervals, and in any case children with only moderate or slight degrees of defective vision are not likely to be detected. Even in these areas, however, cases of blindness, severe squint and severe disease of the eye become known and are offered facilities for treatment. In the case of school children suffering from defective vision the most important means of ascertainment is the system of school medical inspection. The flaw in this system lies in the fact that as a rule vision is not tested until the second routine inspection, i.e., when the child has reached the age of eight. The work of the school nurse is a valuable supplement to the sifting-out process performed by school medical inspection. The school nurse visits the school, in most areas, not less than three times a year, and in others considerably more frequently. During these visits she should be on the look-out for children suffering from eye disease or showing symptoms of defective vision.

Any such children must, of course, be referred to the school doctor for more detailed examination. The work of the school doctor and the school nurse in the ascertainment of children suffering from these defects can be made effective only by the active co-operation of the teachers. The teachers are in daily touch with the children and are in a more favourable position to detect symptoms indicative of a defective special sense than is a school doctor who sees the child only occasionally. Thus if a teacher notes that a child holds the book too close to the eyes, or sits in a stooping position at the desk, or complains of not being able to see the blackboard, or is backward, he should refer the child to the school medical officer for early examination. Similarly, children with inflammatory eye disease, or with squint can be detected by the teacher, who should refer them for special attention. The value of the teacher in our scheme of treatment will be dealt with in detail under " following-up."

Before describing visual acuity and how it is tested in the schools, a short account will be given of sight in young children.

\section{Vision in Young Children}

The child gradually appreciates varying degrees of brightness, learns to focus on near or distant objects by the effort of "accommodation," acquires stereoscopic vision, and judges distance and colour. The development of these processes is slow and conforms, with due allowance for differences in individual children, to a more or less definite pattern. The growth of the eyeball is most rapid in the first two years of life, and by the age of seven it has almost attained its maximum size. A great amount of this growth is due to increase in thickness of the coats of the 
eye, though the increase in the diameter of the cornea between birth and maturity is only $2 \mathrm{~mm}$., or approximately 20 per cent. This increase occurs almost wholly during the first two years of life. The rapidity of growth displayed by the eyeball is even more noticeable than that of the brain, and it is not surprising that the eye should be peculiarly susceptible to injurious influences during early childhood. The process of adaptation which enables the eye to focus rays of light from near as well as from distant sources is known as " accommodation." Most orderly muscular efforts, such as those involved in walking and respiration, involve the alternate use of antagonistic sets of muscles. "Accommodation" for near vision is, however, peculiar since it frequently involves sustained muscular effort extending over a considerable period of time. The muscular effort entailed in continued reading is of a type comparable with that required to hold the arm up for a long time, and symptoms of ocular fatigue may therefore be frequently observed in school children. The normal eye, if overworked, may suffer from fatigue, and such fatigue is likely to occur even more readily in children who have an error of refraction; they are working under a visual handicap. Among the ordinary symptoms of eyestrain are headache, frowning, twitching, blinking, and rubbing of the eyes. There may be, in addition, some inflammation of the external parts of the eye, as blepharitis and conjunctivitis. These external eye diseases are by no means invariably due to eyestrain ; they may be produced by external infection-dust and dirt, by bad nutrition, or by uncleanliness. Since, however, the lymphatic drainage of the eyeball is hampered by sustained ocular effort, such conditions will always tend to be aggravated when any eyestrain is already present.

\section{The Visual Acuity-Snellen's Test}

Under the school medical service the usual procedure is to test children with Snellen's long-distance chart, as a preliminary to refraction by the eye specialist.

The test is usually carried out by school nurses before or at routine inspections in the school. Care should be taken that the illumination of the chart is adequate (the illumination should be at least 10 foot-candles), that the child does not face bright light while being tested, and that the distance from the chart is 20 feet or 6 metres. The standard adopted in most areas is that if a child can read no further than the fifth line $(6 / 12)$ with either eye he is referred for full ophthalmic examination. If, in addition, all cases showing symptoms of eyestrain, no matter what the visual acuity is, are referred, the majority, though not all, children in need of ophthalmic supervision are 
picked out. It should be pointed out, however, that the application of a visual acuity standard does miss a few children, namely, young children with low hypermetropia and emmetropia, who may become myopic later and for whom ophthalmic supervision over a period is desirable. The Board of Education's Committee on Defective Vision (1931) emphasised three main points :-

" (1) The comparative rarity of emmetropia (normal condition) at any age, the condition being observed in only $2-3$ per cent. of children at the age of admission to school. Although its incidence increases with age it does not exceed 10 per cent. among children about to leave school.

" (2) The rarity of myopia (short sight) in children under 5 and the gradual increase in incidence as age advances.

"(3) The great preponderance of hypermetropia (long sight) and even of high hypermetropia at all ages, though the incidence diminishes as age advances."

These conclusions enable us to infer that the eyes of children are in a dynamic state; that at birth the normal condition is one of hypermetropia, which is converted as time goes on to one of emmetropia ; and that over-action in this otherwise physiological process produces a condition of myopia.

The Chief Medical Officer of the Board (1931) writes : " What factors favour this over-action and what differences there are in the process which produces the myopia of slowly progressive type, and that which produces the pathological type which may be accompanied by degenerative changes such as haemorrhage, choroiditis and detachment of the retina, are problems which need further investigation." The Committee previously referred to found that although myopia of even slight degree usually gives rise to some visual defect, the latter may not be of sufficient extent to ensure that all cases are examined by refraction. Similarly, hypermetropia may be of moderate extent, even up to three dioptres, without giving rise to a visual disability severe enough to refer the case for fuller examination. The correction of moderate hypermetropia of children by the provision of spectacles may be of little importance, but it is unquestionable that all cases of myopia, however slight, should be kept under observation. Emmetropia, too, which, if the inference concerning the dynamic state of children's' eyes be correct, may be a stage in the conversion of the hypermetropic to the myopic eye, should be regarded with suspicion in cases where there is a family history of myopia. It is evident therefore that under examination by Snellen's longdistance chart on which we base our preliminary selection of children for refraction by the eye specialist, a certain number of visual conditions requiring observation and possible treatment are missed until the visual acuity defect becomes so pronounced 
as to cause the child to be brought before the ophthalmic surgeon. The only method of completely overcoming this defect in the system of ascertainment would be to arrange that every child, soon after admission to school, is examined by refraction. This perhaps sounds an ideal, though it does not appear to be outside the realm of practical reality. The examination would need to be carried out only once in the school life of the large majority, for most children would reveal a normal condition of eyesight and therefore they would be exempt from re-examination.

Another defect in the system is that children are not subjected to a test of visual acuity until the age of eight. This can be overcome partly by the use of special charts, e.g., the $\mathrm{E}$ chart for illiterate children, though testing by such charts is tedious and the results are unreliable unless the test is carried out by an expert. The variable $\mathrm{E}$ test card, i.e., one in which the $\mathrm{E}$ signs can be rotated in any desired direction, although an old method, is suitable for many purposes. The children should be drilled to turn their extended fingers into the position of the limbs of the $\mathrm{E}$ shown. This method of examination has been proved by tests with mentally defective children to require the smaliest degree of mental work. No recognition of an arbitrary character, or naming of a sign, is required, only the minimal capability of imitation, and the power to put the fingers into the position of the $\mathrm{E}$ shown. No words are required, only the motion of the hand. The Board regard this as the best test card to use when selecting children for admission to blind schools.

Another method is to arrange that nurses in their periodic visits to the schools should test the vision of those children who have learnt to recognise letters, i.e., children between the ages of six and seven. This method is carried out in some areas.

Dr. A. S. Simpson, S:M.O. of Stalybridge, writes in his Report, "I have included an additional routine visual inspection of the six-year-olds, or children who have been in school for a year. 305 children of this group were examined for visual defects and resulted in 35 children being found to require treatment, whilst 10 required to be kept under observation.

In Leeds, nurses undertake the work of testing the five-year-old group either by reading or by matching, and as a result of such testing in 1933, 220 children of various ages under six were noted as requiring refraction, and 328 as requiring to be kept under observation. This means that approximately 550 cases of defective vision which in ordinary cases would not be ascertained until the age of eight were found.

Returning to the $\mathrm{E}$ chart for young children and illiterates I should have mentioned that the chart is utilised fairly extensively in the testing of pre-school and young children, from three years 
old upwards in certain cities of America, notably Pittsburg and Philadelphia. This work is actively encouraged by the National Society for the Prevention of Blindness, who regard the early correction of errors of refraction as a very important factor in the pursuance of their policy. Even admitting the impracticability of using the $\mathrm{E}$ chart in a routine examination of infants, and the unreliability of the results obtained from it, it still remains a matter of importance that some visual test should be applied to children at the earliest possible age. If the nurses in their periodic visits to the schools tested the vision of children of $6+$, as previously stated, it would fill in that hiatus which exists between the time when the child is admitted to school and the intermediate (second-age group, 8 year old) medical examination, and secure examination and appropriate treatment by an ophthalmic surgeon of many cases of defective vision, which in the ordinary course of events would not be discovered until one or two years later. Some years ago the Board suggested that school medical officers should give this matter their earnest consideration, and investigate the practicability of making a test of visual acuity of children at an earlier age than is done under the present system.

\section{Examination and Treatment}

The following are the principal activities which are comprised under the heading " Examination and Treatment ":-

(a) Examination and treatment of defective vision due to errors of refraction.

(b) Examination and treatment of squint.

(c) Examination and treatment of children suffering from diseases of the eye.

(d) Selection, treatment, and supervision of "partially-sighted" and "blind" children.

(e) Testing of colour vision by group and individual tests.

The latter condition has formed the subject of an Article which has appeared elsewhere, so will not be considered here.

(a) Examination and treatment of children with defective vision due to refractive errors.-This forms by far the greater part of the work undertaken by the ophthalmic branch of the school medical service. The work may be discussed under two heads :-

(1) Refraction and ophthalmic examination.

(2) "Following-up" the children who have been treated.

(1) It is essential that the child be prepared for the examination by the instillation of a mydriatic into the eyes. Actual details vary according to the individual surgeon. Atropine ointment is the mydriatic usually preferred, and it is applied for about three nights and mornings, before the examination, but not the morning of the examination. The ointment may be applied daily by the 
nurse at the clinic, or it may be applied by the parent at home. Some authorities regard its action as too prolonged for school purposes. In country districts where distance renders daily attendance at the clinic difficult, homatropine instilled shortly before the examination is used, though this is uncertain of producing complete paralysis of accommodation in young children. Some authorities regard homatropine and cocaine, 2 per cent. solution, used three times at ten minute intervals, as the best mydriatic. The refraction is usually carried out in a school clinic specially fitted-up for this purpose. Full records of the refraction, the condition of the fundus and, if prescribed, the spectacles, should be made at the time of the examination. In the case of myopia a large number of records were surveyed, and it was found that in many cases of moderate or even high conditions of this defect, no record of the fundus condition was made. The Board state " This may be due to the pressure of work of ordinary school clinic work, but it would be more satisfactory to have the assurance that this important part of eye examination is not being overlooked. Another fact of importance and interest is that a considerable number of the records surveyed show that myopes, even of moderate degree, were emmetropes or low hypermetropes during early school life."

The Board's Committee on Defective Vision about 8 years ago suggested tentatively a modification in the Snellen's longdistance test by which it might be made to yield results of greater value. Under present conditions if a child reads $6 / 6$ or $6 / 9$ he is, unless he has subjective symptoms, passed as being normal, yet he may be hypermetropic or slightly myopic. Before recording such a case as normal or not needing correction, the examiner should place a $+1.0 \mathrm{D}$. sphere before the reading eye. If the eye is hypermetropic it will still read $6 / 6$, or possibly even more easily than before. If it is emmetropic or myopic the visual acuity will become less than it was before and in the latter case may diminish to $6 / 36$. Thus the observer should be enabled to make a more accurate and complete ascertainment of those cases which need a fuller examination by retinoscopy, or continued supervision, which under ordinary practice escape detection until their visual defect becomes so obvious as to be recognisable by the ordinary tests at present employed.

The procedure just described was tried out by Mr. Frank Law, F.R.C.S., the Council's Oculist at Willesden, and by Dr. E. L. Roberts, Assistant S.M.O. of Heston and Isleworth. From the experience gained in these two areas it was evident that further trial was necessary, in order to determine the practicability and usefulness of this measure, or a modification of it, in the ordinary routine of school medical inspection. 
Dr. Carr, school oculist, Derbyshire, put the case of ophthalmic work very succinctly some years ago, "The primary objects of a school ophthalmic service must be the preservation of sight, that is to say, preventive ; and the amelioration of defective vision already existent, that is to say, curative. The correction of refractive errors constitutes a preponderating proportion of the work of the ophthalmic surgeon, but it is by no means the most important. A correctly prescribed pair of glasses will improve a patient's vision, or enable him to use his eyes with greater comfort, and very often will do both, and may even have a remarkable effect on his health and ability to profit by instruction, and thereby on the whole of his future career. But by treating a corneal ulcer and getting it to heal before it has done irreparable damage, or by operating on a cataractous eye, the oculist has the satisfaction of preventing blindness in the first instance and of curing it in the second."

(2) Following-up children who have been prescribed glasses. The successful working of arrangements for the treatment of children suffering from defective vision depends on large measure on the efficiency of the arrangements for "following-up " individual children by the school nurses. The importance of this work and the value of the teachers' help will be dealt with in detail. The nurses must keep in touch with children for whom spectacles are prescribed in order to make sure that such spectacles are obtained. Children who require periodical examination, e.g., those with myopia, should attend the clinic at the appropriate intervals determined by the ophthalmic surgeon. The nurses must inspect during their periodic visits to the schools, children for whom spectacles have been provided in order to ascertain whether those children are wearing spectacles, or whether any children through loss or damage need new spectacles.

During their visits to the schools they should test the visual acuity of all children with spectacles at least once a year, and refer any children with a change for the worse in visual acuity for full examination. The teacher is invaluable in this system of "following-up." In most areas it is usual to provide head teachers with lists of children who should be wearing spectacles and to ask for their co-operation in seeing that the children wear them, and in referring any children, who have broken or lost their spectacles, to the clinic. Thus the teacher is important in inducing children for whom spectacles have been prescribed to get them, and wear them. Children, through forgetfulness or intention, fail to bring their glasses to school; glasses by accident or carelessness get broken. These untoward incidents can be avoided or corrected by the teacher, the first by the exercise of discipline, the second by the immediate reference of the case to 
the clinic or medical officer. Without action on her part, children who ought to be wearing spectacles may remain without them for an indefinite period and much harm may result as a consequence. Educational backwardness and disability is one of the symptoms of defective vision. The teachers alone are in a position to recognise this symptom, and their duty is to refer all children who fail to keep up with the normal classwork for full examination by the medical officer, assisting him with their knowledge of the child's visual disability and of any signs of headache or neurotic conditions.

Two other points will be dealt with here, although not strictly belonging to this section. Conditions in the classroom should be made to conform as far as possible with the general principles of hygiene of vision. Attention should be paid to lighting, to the position of blackboards, desks, and books in relation to the posture of children at the desks, and to the position in the classroom of children who suffer, or are suspected of suffering, from defective vision. The second point is that even an apparently simple procedure such as vision testing may have its pitfalls, for apart from the obvious essentials, too often neglected, such as suitable lighting, height of the test card, proper technique on the part of the observer, due regard must be given to the psychological " make-up " of the child. It has been known for a long time that defective lighting of classrooms may contribute towards the production of visual defects or may at any rate have a detrimental effect on defects already existing, but the exact amount of injury due to this factor is as yet by no means clear. Many school doctors have explored this subject. Some years ago the school ophthalmologist of Leicestershire, Mr. C. Walters, inspected a number of schools and he considered that in seven of them the lighting was defective. Four of these were amongst six schools showing the highest percentage of children wearing glasses. He found, of course, that the correlation between defective lighting and a high percentage of children wearing or requiring glasses was by no means exact, but the following table from a report made by him at the time suggests a relationship :-

\begin{tabular}{|c|c|c|c|c|c|}
\hline $\begin{array}{l}\text { School condi- } \\
\text { tions, lighting, } \\
\text { seating } \\
\text { accommoda- } \\
\text { tion. }\end{array}$ & $\begin{array}{c}\text { Total } \\
\text { number of } \\
\text { children. }\end{array}$ & $\begin{array}{l}\text { Number } \\
\text { wearing } \\
\text { glasses. }\end{array}$ & $\begin{array}{c}\text { Percentage } \\
\text { wearing } \\
\text { glasses. }\end{array}$ & $\begin{array}{c}\text { Number } \\
\text { suffering } \\
\text { from eye- } \\
\text { strain. }\end{array}$ & $\begin{array}{c}\text { Percentage } \\
\text { suffering } \\
\text { from eye- } \\
\text { strain. }\end{array}$ \\
\hline Good & 2,281 & 156 & $6 \cdot 7$ & 129 & $5 \cdot 6$ \\
\hline Defective & 1,686 & $14 \pi$ & $8 \cdot 7$ & 181 & 10.7 \\
\hline
\end{tabular}

In concluding this section it can be said that in no branch of the work is this co-operation of the teachers more needed in the prevention, ascertainment and treatment of visual defects in school children. 
Dr. Allardice reporting to the Wakefield Education Committee gave details of what appear to him to be the essentials of a complete ophthalmic scheme and his recommendations arise from the desire to secure the detection of defects at an early stage when treatment could be more effective and would have greater preventive value. His scheme is this:-

(1) The care of the eye-sight of the expectant mother at the ante-natal clinic ;

(2) The treatment of ophthalmia neonatorum at the infant welfare clinic ;

(3) Ophthalmic examination of all entrants to school ;

(4) Reference of external eye disease to minor ailment clinic;

(5) Routine refraction work at 8 and 12 years of age;

(6) Regular re-examination;

(7) Tests for colour blindness ;

(8) Use of the open-air school for myope classes ;

(9) Continuous attention to children entering on secondary education and those beyond 14 years of age.

Many reports of school doctors contain practical recommendations in regard to vision defects and their remedies, by far the largest group of " school diseases" and in some ways obviously the most important.

Dr. Wray, of the Lancashire County Council, has made a special study of the aetiology of defective vision. He concludes :-

(1) That heredity plays a large part in the production of errors of refraction due to mixed astigmatism, and that the maternal influence is the more potent one in passing on the defect to the next generation. 38.2 per cent. of the parents of children affected by mixed astigmatism showed evidence of visual defect ; $49 \cdot 8$ per cent. of the cases affected with this defect showed visual defect amongst other members of the family. Brothers or sisters of the cases examined showed myopic errors frequently, but hypermetropic errors were also found. The familial predisposition to this defect or other defects of sight was found to be about 50 per cent.

(2) More cases of this defect are found in older children, and more frequently in girls than in boys, conditions which are also found in myopia.

(3) More cases are found in schools where lighting is defective.

(4) More cases are found in country schools than in urban schools.

(5) Close relationship between the parents is a potent factor in producing this defect.

(b) Examination and treatment of children with squint.-The successful treatment of squint involves not only the correction of the deformity but the restoration of the function of the squinting 
eye and the re-establishment of binocular vision. Orthoptic treatment by means of the amblyoscope and other instruments has come to the fore of late and is used by an increasing number of authorities. Treatment to teach eyes to act together is carried out by exercises with the amblyoscope. In the case of " squint classes," which have been doubled during the last few years, the error of refraction is carefully corrected and the child is transferred to the squint clinic for treatment to restore the sight of the squinting eye. Vision with glasses is tested, and where the visual acuity of the squinting eye is found to be less than that of the good one the fixing eye is carefully occluded. The only reliable occluder is a black silk patch fixed to the skin with strips of elastoplast leaving a small lower temporal air vent. If the glasses are constantly worn and the good eye is not used, a slow but sure improvement in sight is obtained. When the sight of the bad eye is $6 / 9$, a film of soap is applied to the glasses instead of the paper. The good eye is not uncovered until the sight of the bad eye has improved to its limit. Another treatment consists in utilising a supplementary attachment holding a prism of calculated strength which can be fitted over one or both lenses of a pair of spectacles. The Board cannot regard an ophthalmic scheme as complete without the formation of special arrangements for the treatment of squint and for exercises in fusion training. Further, they state it is essential that such arrangement should be made to apply to children below school age when the chances of obtaining a satisfactory result, particularly as regards the restoration of the function of the squinting eye, are much more promising than when the child is older. Dr. Parry, the S.M.O. for Bristol, wrote (1934): " Cases of squint are detected and treated in as early a stage as possible. Strabismus found in children under school age is reported by members of the Infant Welfare Department, to whom we are indebted for much valuable assistance in this way. A total of 161 new squint cases . . . attended during 1934. Of new cases 85 were under school age and were mostly referred by the Infant Welfare Department."

All children with strabismus should be re-inspected by the eye specialist say at three monthly intervals, and kept under regular supervision.

\section{Myopia}

Myopia generally first shows itself from the age of 8 , when school work begins in earnest-that is, when convergence is first used in excess. Donders reached the classification that myopia exists in three forms-a stationary, a temporarily progressive and a continuously progressive. Dr. Gimblett in the 
East Ham School Medical Officer's Report for 1929 wrote that comparatively few cases were noticed during the first year of school life, more appeared in the second, but by far the greater number were discovered between the ages of eight and twelve.

Dr. Gimblett is of the opinion " that the incidence of myopia is affected by heredity, previous illness (particularly the acute specific fevers), and school competition." He observed that those schools distinguished by a high standard of education and competitive spirit have an incidence of myopia above the average of the other schools of the area. "Out of the 170 myopes, 35 or 20 per cent. were "scholars", while of the total school population of East Ham the "scholars" number $5 \frac{1}{2}$ per cent. It is interesting to note that both the incidence and progress of myopia varied directly with the standard of scholarship in the different schools. Out of the 170 cases 29 had fundal changes when they were first seen, in three of which they became more marked while the child remained under observation. In 15 cases at first free from changes, they appeared later. An examination of the summaries of these cases suggested that the presence of fundal changes is more closely related to the rate of progress of myopia than to the extent of myopia present. As a general rule children show myopia of a comparatively mild form, and though the incidence increases with the age of the.child its severity seems to bear no relation to age, the severe cases being as common in the earlier age groups as in the later. Thus we can say that myopia does not manifest itself to any great extent during the early school life of the child, but becomes more common from the eighth year onwards. In many cases structural peculiarities in the eyes no doubt favour the development of myopia, but it is probable that other cases are directly due to conditions prevailing in the schools which cause undue eyestrain. Dr. James Kerr, many years ago said: "Any child in an elementary school with marked myopia, unless the myopia can be retarded, is in a very dangerous condition as regards vision in later years." In this paper only the milder degrees of myopia are being considered. The higher degrees causing the child to be regarded as " partially-sighted" for educational purposes, will be dealt with in another paper. In the case of a child suffering from " educational " myopia it seems hardly fair to place him under the limited educational opportunities of the special class. On the other hand, does the curriculum and competition of the ordinary school tend to convert the " educational" into the " pathological" myope? The Chief Medical Officer of the Board writes : "How are we to distinguish clinically the early phase of the 'pathological' myope from the ' educational' myope? This is an important point and requires special consideration with a view to modification of the education the 
child receives in the ordinary school or in a school for " partiallysighted 'children." It is interesting to note that in "myope" classes only about one-third of the children are myopes. It is thus a misleading and inaccurate name.

(c) Examination and treatment of children with diseases of the eye.-This branch of an ophthalmic service has particular importance as regards the prevention of defective vision and even of blindness in that it deals with eye disease. At the outset it should be mentioned that the majority of cases of external eye disease, such as conjunctivitis, blepharitis, corneal ulcers, corneal abrasions, keratitis, styes, foreign bodies, etc., are referred in the first place to the minor ailment clinics, and practically all are treated there. In the case of severe inflammatory conditions and chronic states, the child is referred to the special ophthalmic clinic. Here the case will come under expert examination and advice. A few cases, e.g., interstitial keratitis, may need treatment at a hospital or special clinic. In some cases, such as intractable blepharitis or phlyctenular conjunctivitis, the children often receive considerable benefit by a stay in a residential open-air school. Occasionally prolonged treatment under hospital conditions are required on account of the severity of the inflammation or the infectious nature of the disease, e.g., trachoma. Up to three or four years ago the only special hospital school dealing with cases of this character was the White Oak Hospital for Ophthalmia, Swanley, Kent, an institution conducted by the London County Council.

The treatment of diseases of the eye by ultra-violet radiations is dealt with in detail in my book on "Ultra-Violet Therapy." This briefly gives an idea of the work carried out by the ophthalmic service of a Local Authority. All authorities with one exception (Isles of Scilly, 183 children) have established ophthalmic schemes for the treatment of children with defective vision and eye disease. A few of the activities which should be included under a complete ophthalmic scheme have been mentioned. Though children of school age are the primary concern, a medical service of this character cannot be strictly confined to one section of the community ; consequently, matters outside the strict scope of the school medical service have been taken into account. The ophthalmic service has an important duty to perform in the selection and supervision of children who, on account of defective vision, are in need of special educational provision, i.e., " partially-sighted" and "blind" children. This part of the work will be dealt with in a future paper.

There are, of course, visual defects which do not depend on errors of refraction. Mr. Paterson, the school oculist to the Darlington Education Committee, reported a few years ago the 
discovery of a number of cases of night blindness, the cause being xerophthalmia. The condition appears to have been quickly remedied by adding to the children's dietary an adequate supply of foods containing vitamin A. In all areas there are cases of children presenting ocular symptoms in whom an exhaustive examination discloses no physical defect. The percentage of such cases varies considerably in different places, but in Portsmouth, Dr. W. S. Inman found that 25 per cent. of children attending the Eye Clinic required no active treatment. They were mostly " nervous " children, and he discussed the question as to whether their symptoms were produced by disharmony of mind rather than of body, and concluded by saying: " Child guidance clinics are being formed in London, and it cannot be long before they exist in every educational centre in the country. One method of recognising the nervous child will be by the disparity between the severity of the symptoms and the condition of the eyes. A happy, healthy child does not complain without just cause. If an ocular cause cannot be found and no other adequate organic explanation of the symptoms is present the aid of a psychological department should be available."

At Liverpool in 1929 an exhaustive investigation of hereditary optic atrophy (Leber's disease) was carried out, and the findings gave accurate information as to the transmissibility of this serious defect. The results of this investigation have been summarised and are as follows :-

(1) The disease is transmitted according to Mendelian laws of heredity appertaining to dominant and recessive characteristics, and is attributable to a dominant factor. Consequently, in the event of the marriage of any affected case with a normal individual, it is possible to predict that approximately half the offspring will also develop the disease. Further, in the case of unaffected members, it is quite safe for them to marry as the disease will not be transmitted to their descendants.

(2) The disease is not sex limited as was formerly thought, both males and females suffering from and transmitting the disease in approximately equal proportions.

(3) So far as the cases in which it has been possible to make a personal investigation are concerned, the disease has manifested itself in childhood and the onset is not delayed until adult life, as was thought by Leber.

The Board consider it essential that there should be on the staff of the ophthalmic service an ophthalmic surgeon of consultant standing. Not only is he an adviser, but also an executive officer in so far as he carries out treatment of certain special cases. Most of the work of an ophthalmic service is carried out by full-time officers on the staff of the school medical service. Many children 
with defective vision due to simple errors of refraction are treated by assistant medical officers who have had the requisite experience. It is advisable, however, that all treatment for defective vision be carried out by officers specially qualified and with special experience. There are certain duties under the ophthalmic scheme which should always devolve upon the specialist. They are as follows :-

(a) Examination and treatment of all cases of myopia.

(b) Examination and treatment of all cases of defective vision due to complicated errors of refraction which will be referred by assistant school medical officers.

(c) The supervision of clinics for the treatment of squint.

(d) Examination and treatment of all cases of severe and protracted eye disease.

(e) The selection, examination and supervision of all " partially-sighted " children.

$(f)$ The certification of children as " blind " under the Education Act and the supervision of such children.

Act.

Education Authorities Schemes for dealing with visual defects are complete (only one Authority does not make provision) throughout the country, and there is hardly a child who has not the opportunity to have such defects corrected. The number of children examined by ophthalmic surgeons during 1936, the last year for which a Report is available, was over a quarter of a million, which represented over 5 per cent. of the total school population, an indication not merely of comprehensive treatment but also of the systematic re-examination necessitated by alterations in the vision of individual children. It would be fairly safe to say that only a very small proportion of children leave school without having their visual defects corrected so far as human skill can do this.

\section{TABLE I}

Tables showing the Staff and work done under the Ophthalmic Schemes of Local Authorities during the year 1936. SPECIALIST STAFF.

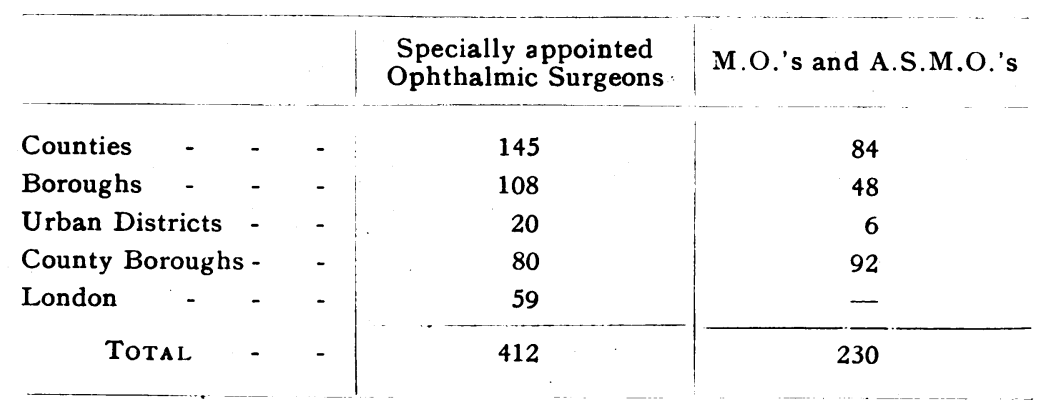


School Ophthalmic Service

TABLE II

Incidence of Defective Vision and Squint, 1936.

\begin{tabular}{|c|c|c|c|c|c|c|c|}
\hline \multirow{2}{*}{ TYPE C } & \multirow{2}{*}{ AREA } & & \multirow{2}{*}{$\begin{array}{l}\text { Number of } \\
\text { children } \\
\text { inspected at } \\
\text { routine } \\
\text { inspections } \\
\text { (entrants } \\
\text { excepted) }\end{array}$} & \multicolumn{3}{|c|}{$\begin{array}{l}\text { Number of cases of defective vision } \\
\text { requiring treatment }\end{array}$} & \multirow{2}{*}{$\begin{array}{c}\text { Percentage } \\
\text { of children } \\
\text { with } \\
\text { defective } \\
\text { vision and } \\
\text { squint }\end{array}$} \\
\hline & & & & $\begin{array}{l}\text { Errors of } \\
\text { Refraction }\end{array}$ & Squint & Total & \\
\hline Counties & - & - & 438,290 & 31,153 & 4,743 & 35,896 & $8 \cdot 2$ \\
\hline Boroughs & - & - & 161,365 & 11,206 & 1,732 & 12,938 & $8 \cdot 0$ \\
\hline Urban Di & istricts & - & 30,099 & 2,737 & 502 & 3,239 & $10 \cdot 8$ \\
\hline County B & Boroughs & - & 384,912 & 29,795 & 5,411 & 35,206 & $9 \cdot 1$ \\
\hline London & - & - & 134,225 & 12,768 & 946 & 13,714 & $10 \cdot 2$ \\
\hline To & TAL & - & $1,148,891$ & 87,659 & 13,334 & 100,993 & $8 \cdot 8$ \\
\hline
\end{tabular}

TABLE III

Number of cases of Defective Vision and Squint and other Eye Defects dealt with during the year 1936.

\begin{tabular}{|c|c|c|c|c|c|c|c|}
\hline \multirow[b]{2}{*}{ TYPE OF } & \multirow[b]{2}{*}{ AREA } & \multicolumn{3}{|c|}{ Defective Vision and Squint } & \multicolumn{3}{|c|}{ Other Eye Defects } \\
\hline & & $\begin{array}{c}\text { Under Local } \\
\text { Education } \\
\text { Authorities' } \\
\text { Schemes }\end{array}$ & Otherwise & Total & $\begin{array}{c}\text { Under Local } \\
\text { Education } \\
\text { Authorities } \\
\text { Schemes }\end{array}$ & Otherwise & Total \\
\hline Counties & - & 86,046 & 2,881 & 88,927 & 2,465 & 113 & 2,578 \\
\hline Boroughs & - & 34,517 & 1,114 & 35,631 & 1,469 & 139 & 1,608 \\
\hline Urban Dis & stricts - & 7,876 & 205 & 8,081 & 472 & 29 & 501 \\
\hline County Bor & roughs & 91,088 & 3,412 & $.94,500$ & 1,939 & 172 & 2,111 \\
\hline London & - & 37,570 & 1,006 & 38,576 & 2,000 & - & 2,000 \\
\hline TotaL & & 257,097 & 8,618 & 265,715 & 8,345 & 453 & 8,798 \\
\hline
\end{tabular}

* The figure for these defects is included in another Table.

TABLE IV

Provision for treatment of Defective Vision by Local Education Authorities.

\begin{tabular}{|c|c|c|c|c|c|c|}
\hline & Counties & Boroughs & $\begin{array}{c}\text { Urban } \\
\text { Districts }\end{array}$ & $\begin{array}{c}\text { County } \\
\text { Boroughs }\end{array}$ & $\begin{array}{c}\text { Total } \\
1936\end{array}$ & $\begin{array}{c}\text { Number not } \\
\text { making } \\
\text { provision in } \\
1936\end{array}$ \\
\hline $\begin{array}{l}\text { (1) Treatment of } \\
\text { Defective } \\
\text { Vision - }\end{array}$ & 62 & 146 & 24 & 83 & 315 & 1 \\
\hline $\begin{array}{l}\text { (2) Supply of } \\
\text { Spectacles - }\end{array}$ & 61 & 145 & 24 & 83 & 313 & 3 \\
\hline
\end{tabular}




\section{TABLE $\mathrm{V}$}

The number of School-Clinics provided by Local Education Authorities for the treatment of Defective Vision and Squint during the last ten years is as follows:

\begin{tabular}{|c|c|c|c|c|c|c|c|}
\hline & YEAR & & Number of Clinics & YE & & & Number of Clinics \\
\hline 1927 & - & - & 569 & 1932 & - & - & 660 \\
\hline 1928 & - & - & 593 & 1933 & - & - & 673 \\
\hline 1929 & - & - & 606 & 1934 & - & - & 670 \\
\hline 1930 & - & - & 633 & 1935 & - & - & 694 \\
\hline 1931 & - & - & 644 & 1936 & - & - & 718 \\
\hline
\end{tabular}

\section{TABLE VI}

Number of Hospitals with which Local Education Authorities have made arrangements for the treatment of defects of vision, year 1936.

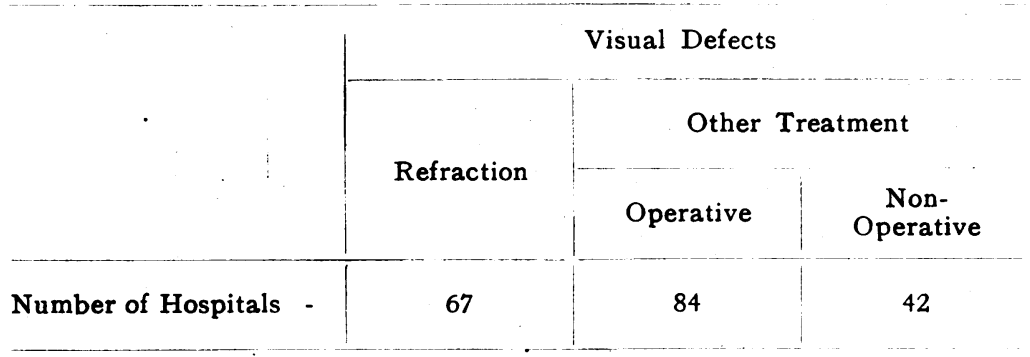

\section{ANNOTATION}

\section{Ophthalmic Casualties in Air Raids}

It seems that in the event of air raids the special hospitals in the London area and other large centres will be commandeered for the treatment of casualties of all kinds and that their rôle will be similar to the general hospitals.

It is desirable that ophthalmic casualties should be dealt with by units trained for this work and that they should be evacuated from the theatre of air raids at the earliest opportunity after appropriate treatment has been applied. There is no need for any ophthalmic case to remain in the danger zone. Gas cases and minor injuries 